\title{
Resistance of ultra high performance fibre reinforced concrete to projectile impact
}

\author{
P. Máca \& R. Sovják \\ Experimental Centre, Faculty of Civil Engineering, \\ Czech Technical University in Prague, Czech Republic
}

\begin{abstract}
The aim of this work is to describe the resistance of ultra high performance fibre reinforced concrete (UHPFRC) to projectile impact. The main goal is to find an optimum fibre content in the UHPFRC mixture with respect to the resistance to projectile impact, strength and workability. In addition, the authors describe the formulation process of UHPFRC that was developed without using heat treatment, pressure or a special mixer. Only ordinary materials available commercially in the Czech Republic were utilized throughout the process. The compressive strength of the resulting UHPFRC mixtures exceeded $150 \mathrm{MPa}$ after 28 days and the flexural strength in three point bending was in the range of $40 \mathrm{MPa}$. Such high strengths were achieved due to the utilization of the high strength fibres and low water-to-binder ratio. The resistance of the UHPFRC to projectile impact is evaluated experimentally. Slabs made of UHPFRC with different fibre content were hit by deformable projectiles. The magnitude of the impact damage induced in the concrete specimens was evaluated from the average crater diameter and penetration depth. It was verified experimentally that an increase of fibre content has no significant effect on penetration depth while decreasing crater diameter. It was found that with respect to the resistance to projectile impact, strength and acceptable workability the optimal fibre content in the UHPFRC mixture is between 2 and $3 \%$ by volume.

Keywords: cementitious composite, fibre reinforced concrete, optimization, local damage, mechanical properties, projectile impact.
\end{abstract}

\section{Introduction}

Increasing requirements for durability, safety and security of concrete structures push its development still further. High rise buildings and other structures of 
strategic importance such as government buildings and television towers have become a symbol of developed cities worldwide. However, such structures are threatened by possible extreme-load events like earthquakes, gas explosions, car or plane impact and, in recent years, terrorist attacks. New hi-tech materials such as ultra-high performance fibre reinforced concrete (UHPFRC) are ideal for applications where high compressive and tensile strength, small thickness and high energy absorption capacity are required. For instance, the utilization of high strength concrete allowed for the construction of many skyscrapers around the world. In addition, UHPFRC significantly improves blast resistance of cladding panels and walls while maintaining its standard thicknesses and appearance [1].

UHPFRC can be characterized as a composite containing large volume of steel fibres, low water-binder ratio, high microsilica content and absence of coarse aggregate i.e. larger than $4 \mathrm{~mm}$ [2]. It has outstanding material characteristics such as self-consolidating workability, very high mechanical properties and low permeability which results in excellent environmental resistance [3]. Typical strengths are 150 to $200 \mathrm{MPa}$ in compression and 7 to $15 \mathrm{MPa}$ in uniaxial tension. Moreover, these materials exhibit strain hardening under tension $[4,5]$ and high energy absorption capacity $[6,7]$. In addition, they show improved structural behaviour when compared to conventional concrete and smaller spalling and scabbing under impact loading. Improved resistance to impact loading in terms of penetration depth and crater diameter can be achieved through decreased water-to-cement ratio and increased concrete compressive strength. Addition of steel fibres to the mixture tends to reduce the crater diameter while it has no significant effect on penetration depth [8].

To prevent structural collapse and people's injuries, high-rise structures from high strength materials must possess a much greater resistance to impact loading. It is well known that traditional fibre reinforced concrete (FRC) with normal strength matrix has large capacity to absorb energy [9]. However, several authors $[6,7,10,11]$ suggest that UHPFRC has much greater capability to absorb energy both in quasi-static and dynamic loading. Vejmelkova et al. [12] suggest that the fire and explosion resistance of such composite can be increased by using hybrid fibre reinforcement, i.e. polypropylene in combination with steel fibres.

This paper describes both formulation of UHPFRC mixture, measurement of its mechanical properties and its resistance to projectile impact. Compressive strength, secant modulus of elasticity, uniaxial tensile strength on dog-bone specimens and flexural strength were measured during the research work. In addition, resistance of UHPFRC to impact loading was determined using impact of deformable projectile on the slabs. A deformable projectile (7.94 g) was used with muzzle velocities ranging between 692 to $728 \mathrm{~m} / \mathrm{s}$.

\section{Mixture optimization}

\subsection{Mixing procedure and sample preparation}

During the mixing of UHPC, it is very important to achieve good workability, particle distribution and packing density. In comparison to normal strength 
concrete UHPC contains more constituents and finer particles. Several researchers recommend $[2,4]$ to mix all fine dry particles first before adding water and high-range water reducer (HRWR). It is because small particles tend to agglomerate and it is easier to break these chunks when the particles are dry. The specific mixing procedure was as follows: In the first step both types of aggregate (A) and SF were mixed for five minutes. In the second step C and GP were mixed for another five minutes. At the end of the procedure water and HRWR were added. The addition of HRWR was gradual. The mixture became fully workable after another 5 minutes.

In case of UHPFRC fibres were added gradually into the flowable mixture to avoid chunks formation during the last 5 minutes of mixing. The shear action of fibres helped to destroy any remaining agglomerates in the mixture, thus improving workability. The total mixing time was 15 minutes for UHPC mixtures and 20 minutes for UHPFRC. A food-type mixer with a capacity of 101 was used to prepare the samples.

\subsection{Cementitious matrix design and optimization}

In the first phase of the research, several concrete mixtures without fibres were produced to find the best combination of constituents with respect to maximal compressive strength and workability. High particle packing density is a key property of ultra-high compressive strength of concrete. Therefore the mixture design was based on optimizing the particle packing density of sand (S), silica fume (SF), glass powder (GP) and cement (C). Improving particle packing was achieved mainly by changing the matrix composition and proportions and by selecting ranges of particles for sand. In total 24 mixture designs were tested. Flexural strength was evaluated on $40 \times 40 \times 160 \mathrm{~mm}$ prisms and compressive strength on the halves of these prisms following CSN EN 1015-11. Workability was tested according to CSN EN 1015-3 using standard flow table.

The first mixture was designed following the proportions of C:SF:GP recommended by Wille et al. [2] as 1:0.25:0.25 with a water binder (w/b) ratio 0.2 . Subsequent changes in the most important parameters such as high-range water reducer (HRWR), water content (W), amount of aggregate (A), SF, and GP led to an optimized cementitious matrix in terms of compressive strength and workability. From the 24 tested mixtures, two best performing cementitious matrix compositions denoted as UHPC2 and UHPC3 are shown in table 1 along with the first starting mixture (UHPC1). Table 1 also shows basic material properties of the selected mixtures. In the "average spread" row a diameter of paste spread measured after filling and removing the standard cone and impacting the table 15 times is compared.

\subsection{Fibre addition}

In the second step of the optimization process straight steel fibres were added up to $3 \%$ of volume in replacement of the equivalent volume of coarser sand to the best performing mixture UHPC3 forming UHPFRC3 mixtures. Straight fibres were used because it is known that they provide a good trade-off between tensile 
Table 1: $\quad$ Design of mixtures without fibres.

\begin{tabular}{|c|c|c|c|}
\hline \multirow{2}{*}{ Type of component } & UHPC1 & UHPC2 & UHPC3 \\
\cline { 2 - 4 } & \multicolumn{3}{|c|}{ Proportions by weight } \\
\hline Cement CEM I 52,5R & 1 & 1 & 1 \\
\hline Silica fume & 0.25 & 0.25 & 0.25 \\
\hline Glass powder & 0.25 & 0.25 & 0.25 \\
\hline Water & 0.25 & 0.22 & 0.22 \\
\hline HRWR: Sika SVC 20 Gold & 0.031 & - & 0.031 \\
\hline HRWR: Sika ViscoCrete 20He & 0.019 & - & 0.019 \\
\hline HRWR: Sika ViscoCrete 30He & - & 0.025 & - \\
\hline HRWR: Sika ViscoCrete 1035 & - & 0.025 & - \\
\hline Fine sand 0.1/0.6 mm & 0.42 & 0.42 & 0.42 \\
\hline Fine sand 0.3/0.8 mm & 1 & 1 & 1 \\
\hline Water/binder ratio & 0.2 & 0.176 & 0.176 \\
\hline Average spread [mm] & 140 & 150 & 150 \\
\hline Avg. compr. strength [MPa] & 110.0 & 132.2 & 141.9 \\
\hline Avg. flexural. strength [MPa] & 17.6 & 20.8 & 22.1 \\
\hline
\end{tabular}

properties and workability of the composite. The fibres were $13 \mathrm{~mm}$ long with a diameter of $0.15 \mathrm{~mm}$ and tensile strength of $2800 \mathrm{MPa}$. Mixture proportions can be found in Table 2. The second number after the type of matrix denotes the fibre content by volume. For instance UHPFRC3-2 means mixture containing 2\% of fibres which is based on the UHPC 3 matrix design. The mixing procedure was the same as for previous samples. For each mixture (UHPC3, UPFRC3-1, UHPFRC3-2, UHPFRC3-3) three cylinders with a diameter of $100 \mathrm{~mm}$ and height of $200 \mathrm{~mm}$, three dog bone specimens, three $40 \times 40 \times 160 \mathrm{~mm}$ prisms and two $300 \times 400 \times 50 \mathrm{~mm}$ slabs were cast.

Table 2: $\quad$ Final mixtures design.

\begin{tabular}{|c|c|c|c|}
\hline \multirow{2}{*}{ Type of component } & UHPFRC 3-1 & UHPFRC 3-2 & UHPFRC 3-3 \\
\cline { 2 - 4 } & \multicolumn{3}{|c|}{ Proportions by weight } \\
\hline Cement CEM I 52,5R & 1 & 1 & 1 \\
\hline Silica fume & 0.25 & 0.25 & 0.25 \\
\hline Glass powder & 0.25 & 0.25 & 0.25 \\
\hline Water & 0.22 & 0.22 & 0.22 \\
\hline HRWR: Sika SVC 20 Gold & 0.031 & 0.031 & 0.031 \\
\hline HRWR: Sika ViscoCrete 20He & 0.019 & 0.019 & 0.019 \\
\hline Fine sand 0.1/0.6 mm & 0.42 & 0.42 & 0.42 \\
\hline Fine sand 0.3/0.8 mm & 0.9 & 0.8 & 0.7 \\
\hline Fibres & 0.1 & 0.2 & 0.3 \\
\hline
\end{tabular}




\section{Mechanical and impact properties measurement}

\subsection{Compressive strength and modulus of elasticity}

Compressive strength and secant modulus of elasticity were measured on cylinders with $100 \mathrm{~mm}$ diameter and height of $200 \mathrm{~mm}$. Because the strength of the best available capping material $(100 \mathrm{MPa})$ was significantly lower than the expected measured strengths, tops of the cylinders were cut off and grinded. Compressive strength was measured on cylinders by monotonic increments of load with average speed of $36 \mathrm{MPa} / \mathrm{min}$ up to the level of $70 \%$ of the expected compressive strength. At this point loading was switched to deformation control with a speed of $0.48 \mathrm{~mm} / \mathrm{min}$ for about 2 minutes in order to measure peak and post peak behaviour. In the softening branch speed was increased to $1.2 \mathrm{~mm} / \mathrm{min}$.

Modulus of elasticity was measured using two extensometers with a $150 \mathrm{~mm}$ base, attached to the sides of the cylinder specimen. A hydraulic loading machine DSM2500-100 was used and the loading procedure was stress controlled. In the first step the specimens were loaded to $1 / 3$ of expected maximal compressive strength - in this case $50 \mathrm{MPa}$ - for 60 seconds. Afterwards the specimens were unloaded to $5 \mathrm{MPa}$. This procedure was repeated three times. The secant modulus of elasticity was calculated from the third unloading branch. In the second step, the specimens were loaded until failure and compressive strength was determined.

\subsection{Direct tensile tests}

Direct tensile tests were carried out on dog-bone shaped specimens without a notch. The length of the specimens was $330 \mathrm{~mm}$ and the cross-section of the narrowed part was $30 \times 30 \mathrm{~mm}$. The specimens are categorized with respect to volumetric content of steel fibres as outlined in table 2 . Three specimens from each category were tested. All specimens were cast in layers which led to alignment of fibres in the direction of the applied load.

The direct tensile tests were performed on MTS loading machine. The specimens were mounted into specially developed grips as shown in fig. 1. The extension in the elastic region was measured with two foil tensometers glued on both narrow sides. After the localization of a crack the extension was measured with two LVDTs mounted with a special frame on the dog-bone specimen as can be seen in fig. 1. The loading speed was $0.1 \mathrm{~mm} / \mathrm{min}$ for specimens without fibres. In case of specimens containing fibres the loading was performed in two steps. The loading speed in the first step was $0.3 \mathrm{~mm} / \mathrm{min}$ until the load decreased to approximately $70 \%$ of the maximal load. In the second step the loading speed was increased to $0.5 \mathrm{~mm} / \mathrm{min}$. This loading procedure was chosen in order to speed up the test as deformation after the crack opening was in order of magnitude larger than deformation measured until peak load.

\subsection{Projectile impact measurement}

Resistance to impact loading was performed on UHPC and UHPFRC rectangular slabs with dimensions $300 \times 400 \mathrm{~mm}$ and thickness of $50 \mathrm{~mm}$. As the presence of 


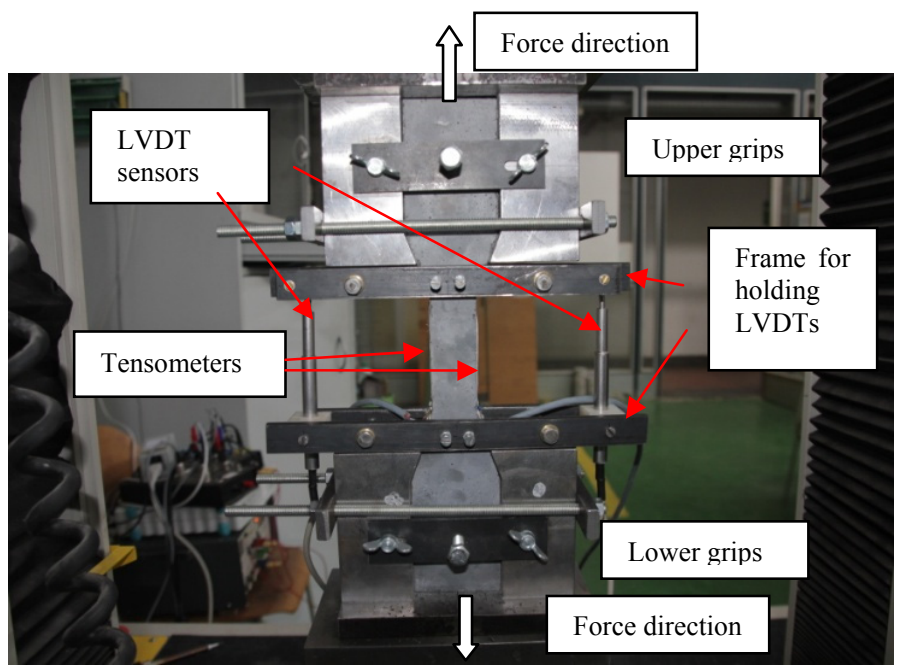

Figure 1: $\quad$ Setup of the direct tensile stress test.

reinforcing bars has negligible effect on perforation resistance of the slabs [13], no reinforcing bars were utilised to construct the specimens. Impact was simulated as a hit of deformable projectile fired from the gun on the UHPFRC slab. The setup of the experiment is shown in fig. 2. Distance to the slab was 20 meters and muzzle velocity was measured with a shooting chronograph located approximately 2 meters from the gun muzzle. $7.62 \times 39$ FMJ soft-core ammunition was used and the weight of the projectile was 123 grains $(8 \mathrm{~g})$. The average muzzle velocity was $712 \mathrm{~m} / \mathrm{s}$ with the average impact energy of $2000 \mathrm{~J}$. In total 8 slabs were tested for impact loading. That is two slabs from each type of mixture (UHPC3, UHPFRC3-1, UHPFRC3-2 and UHPFRC3-3). Extent of damage caused by the impact was defined by the penetration depth and crater diameter. Average value of crater diameter was determined from four measurements taken in four directions.

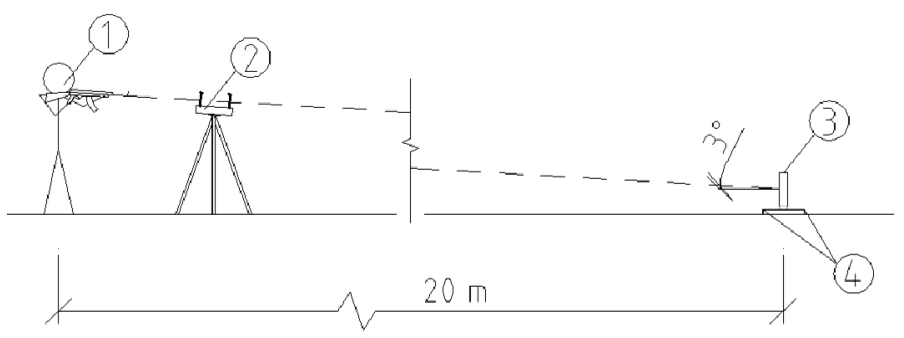

Figure 2: Setup of the impact loading test (1-shooter, 2-shooting chronograph, 3-UHPFRC slab, 4-mount for UHPFRC slab). 
Each test specimen was placed in a special mount (4) developed for the purpose of this study in order to prevent movement of the specimen during impact. The mount was provided with four screws located in the corner of the specimen approximately $50 \mathrm{~mm}$ from both edges in order to simulate point supports. Each specimen was placed in the mount that the projectile would hit the centre of the specimen under the slight angle around $3^{\circ}$ which was considered as negligible.

\section{Results and discussion}

\subsection{Mechanical properties}

Table 3 shows determined compressive strength, flexural strength and secant modulus of elasticity of the developed mixtures with respect to fibre content. The values presented in the table are averages from three samples. It can be seen that the average highest compressive strength of $151.7 \mathrm{MPa}$ was achieved for $2 \%$ volumetric content of fibres. In correspondence with that the highest average secant modulus of elasticity of $56.9 \mathrm{GPa}$ was measured for $2 \%$ fibre volume. The highest flexural and direct tensile strength was achieved for samples containing $3 \%$ of fibres by volume. Direct tensile stress was measured using apparatus shown in fig. 1. It must be noted that this measurement is not ideal as cracks in all cases localized near the bottom grips. The research team believes that this is caused due to stress localization in this area.

Table 3: $\quad$ Average mechanical properties of the UHPFRC mixtures.

\begin{tabular}{|c|c|c|c|c|}
\hline Average mechanical property & UHPC 3 & UHPFRC 3-1 & UHPFRC 3-2 & UHPFRC 3-3 \\
\hline Workability - spread [mm] & 200 & 220 & 225 & 190 \\
\hline Compressive strength [MPa] & 132.4 & 148.5 & 151.7 & 148.1 \\
\hline Flexural strength [MPa] & 9.9 & 27.0 & 40.1 & 47.5 \\
\hline Direct tensile strength [MPa] & 6.6 & 7.8 & 9.9 & 10.9 \\
\hline Modulus of elasticity [GPa] & 41.1 & 45.1 & 56.3 & 51.5 \\
\hline
\end{tabular}

The results of the uniaxial tensile tests of specimens containing $0,1,2$ and $3 \%$ of fibres respectively are presented in fig. 3. The stress-strain curves in fig. 3 are average curves from three samples to keep the chart as clear as possible. The figure is divided into two parts that are typical for UHPFRC behaviour: a) linearelastic and strain hardening part, which includes the linear-elastic stress rise and the strain hardening part of stress-strain diagram. It is possible to say, that energy dissipation is volumetric in this part; b) the softening part in which the energy is dissipated in a localized crack at the crack surface.

Fig. 3 a) shows the stress-strain relationship in the strain hardening part of the curve. The stress is calculated by dividing the measured force by the reduced cross-section of the dog bone specimen $(30 \times 30 \mathrm{~mm})$. Strain values were determined from the average strain measured by two foil tensometers, which were glued on the side of the specimen. Fig. $3 \mathrm{~b}$ ) provides the relation between stress and total crack width during softening. The total crack width was 
a)

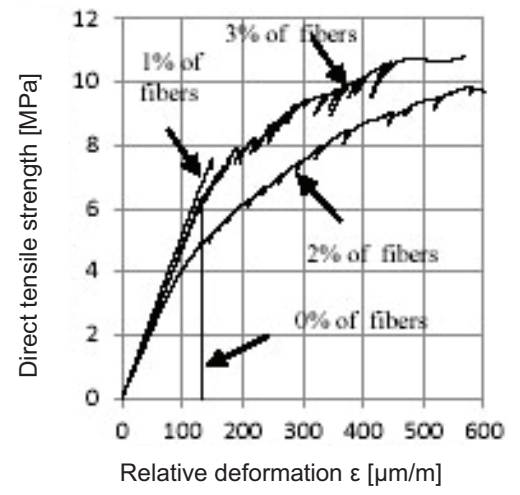

b)

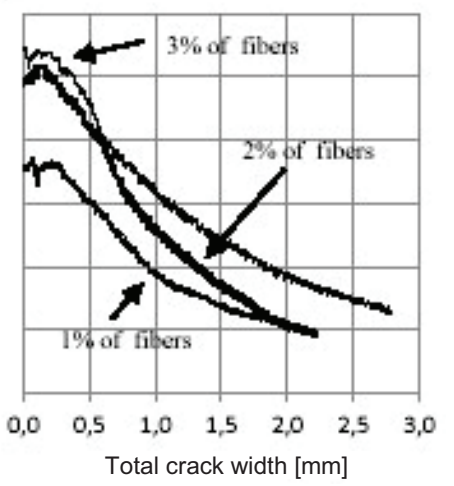

Figure 3: Uniaxial tensile behavior of UHPFRC: a) linear-elastic part and strain hardening and b) softening.

measured as an average from two LVDTs which spanned over the entire reduced cross-section portion of the specimen.

\subsection{Resistance to projectile impact}

The results of the impact tests including response type, muzzle velocities, average crater diameter, penetration depth, spalling and scabbing are presented in the table 4. Response type was classified in accordance with the convention used in Vossoughi [14] perforated - P (the projectile passed through the specimen entirely), perforation limit - PL (projectile was stuck), perforated and then bounced - PB (the projectile went through the slab and then bounced back) and unperforated - UP (panel was punched but the projectile bounced back).

It was verified experimentally that increase of fibre content have no significant effect on penetration depth while slightly decreasing crater diameter. Crater diameters were $42-50 \%$ smaller than those in plain concrete (i.e. $0 \%$ of fibre content). However, further increase of fibre content beyond $2 \%$ has no effect on crater diameter either (fig. 4).

Table 4: $\quad$ Effect of steel fibres on crater diameter and penetration depth.

\begin{tabular}{|c|c|c|c|c|c|c|c|c|}
\hline & \multicolumn{2}{|c|}{ UHPC 3 } & \multicolumn{2}{c|}{ UHPFR 3-1 } & \multicolumn{2}{c|}{ UHPFRC3-2 } & \multicolumn{2}{c|}{ UHPFR3-3 } \\
\hline Fibre content (\%) & 0 & 0 & 1 & 1 & 2 & 2 & 3 & 3 \\
\hline Specimen number & 1 & 2 & 1 & 2 & 1 & 2 & 1 & 2 \\
\hline Muzzle velocity (m/s) & 710 & 714 & 715 & 728 & 692 & 706 & 716 & 718 \\
\hline Response type & $\mathrm{P}$ & $\mathrm{P}$ & UP & UP & UP & UP & UP & UP \\
\hline Crater diameter (mm) & - & 148 & 68 & 101 & 80 & 68 & 83 & 63 \\
\hline Penetration depth (mm) & N/A & N/A & 20 & 21 & 19 & 21 & 19 & 19 \\
\hline Mass loss (g) & N/A & N/A & 53 & 122 & 63 & 44 & 50 & 170 \\
\hline Spalling (g) & N/A & N/A & 53 & 108 & 63 & 44 & 50 & 85 \\
\hline
\end{tabular}



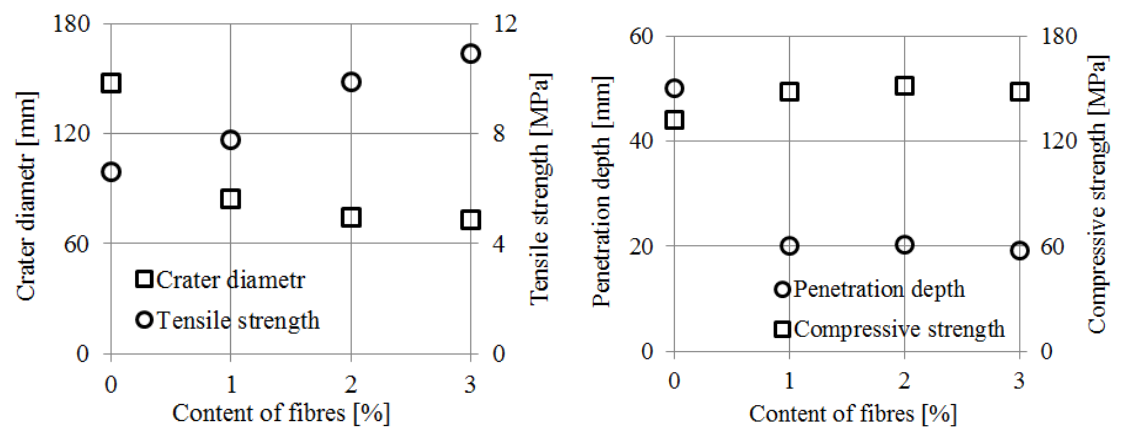

Figure 4: $\quad$ Effect of steel fibres on crater diameter and penetration depth.

Perforation through the slab occurred in the case of plain concrete specimen. In case of fibre reinforced concrete the slabs were not perforated and the projectile bounced back. The average penetration depth was reduced from $20.5 \mathrm{~mm}$ to $20.0 \mathrm{~mm}$ and $19.0 \mathrm{~mm}$ for fibre reinforced concrete slabs as the content of fibres increased from $1 \%$ to $2 \%$ and $3 \%$, respectively (Fig. 4). Therefore it is evident that increasing the fibre content beyond $1 \%$ has only minor effect on penetration depth. Figure 5 depicts the damage caused to the front and rear side of the plain concrete made of UHPC mixture where projectile perforated the slab. Macrocracks propagated through the specimen to the rear side, splitting the specimen into four pieces. Crater diameter was measured to be $148 \mathrm{~mm}$. All plain concrete slabs were perforated with the projectile, whereas no slab made of fibre reinforced concrete was perforated and the penetration was not larger than $20.5 \mathrm{~mm}$ (Fig. 6).

a)

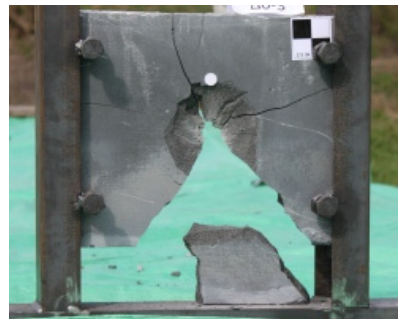

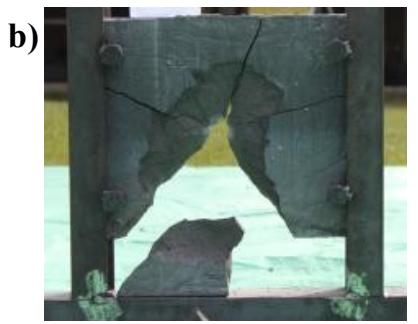

Figure 5: $\quad$ Front (a) and rear (b) damage of a $50 \mathrm{~mm}$ tick UHPC slab.
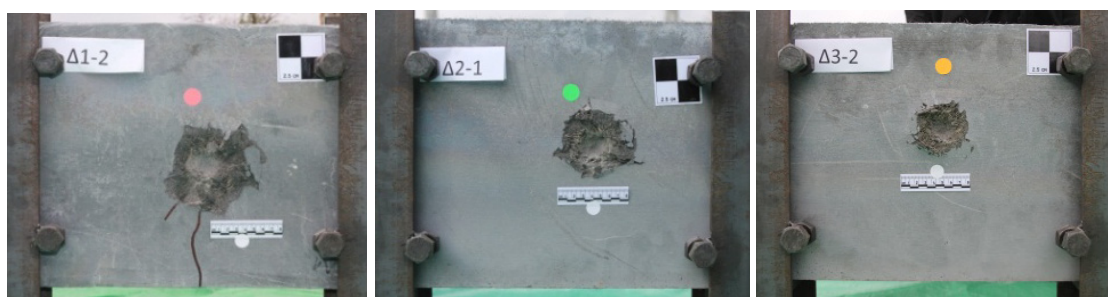

Figure 6: Typical front damage of a $50 \mathrm{~mm}$-tick UHPFRC slab containing 1, 2 and $3 \%$ of fibres, respectively. 
Figures 5 and 6 show typical post-test photographs of the front and the rear side of the slabs, whereas typical cross section damage and failure mechanism of the UHPFRC slab after the projectile impact including compaction at the front side and tensile cracking on the rear side is shown in fig. 7. UHPFRC slabs sliced in the middle of the specimen after the projectile impact (fig. 7) show crater caused by the spalling from the front side and the scabbing from the rear side.

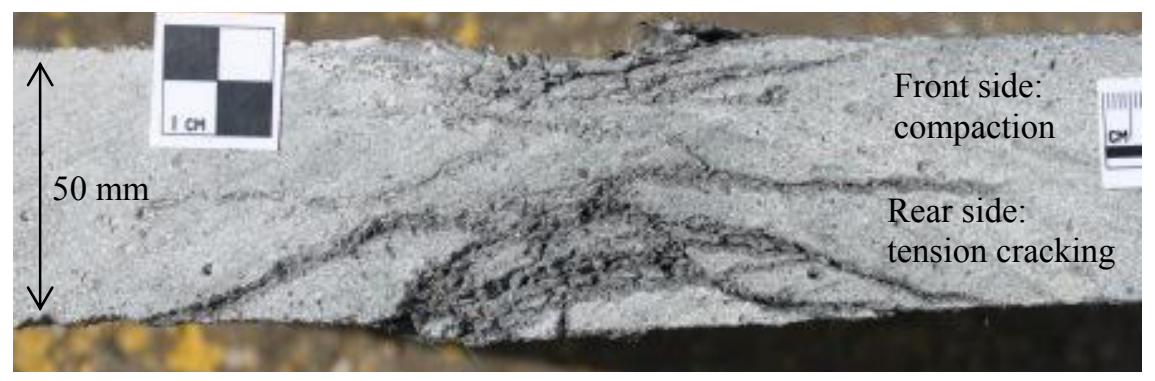

Figure 7: Typical cross section damage of the UHPFRC slabs.

\section{Conclusions}

The research described herein has shown that it is possible and relatively simple to develop a UHPFRC without the need for special curing such as heat or pressure. It was also shown that it is possible to use standard laboratory equipment such as food-type and horizontal-pan mixers for mixing high performance cementitious composites. The initial strategy was to increase workability by optimizing the packing density of the mixture and using different types of HRWR. A spread of the paste measured during the simple flow-table test was found to provide good indication of workability. In addition, results from three-point bending (flexural) and compressive strength were utilized during the optimization process. All materials used in this research were commercially available in the Czech Republic.

The experimental work also showed the importance of strict mixing procedure. Especially mixing times must be strictly adhered to. In addition, it was also showed that mixtures containing more than $3 \%$ of fibres by volume have very bad workability and more optimization and usage of different HRWR and mixing techniques is needed in this area. The future research will focus on measurement of fracture energy of UHPFRC under different strain rates and on further optimization of the matrix composition.

The main findings of our research are as follows:

- An optimization of ultra-high performance cementitious composite was undertaken comprising laboratory tests on 24 mixtures with respect to its compressive strength, flexural strength and workability

- Based on the former parameters the final mixture was chosen for further expertise dealing with different amount of fibre content. 
- Addition of fibres to the mixture increased the mechanical properties of the UHPFRC. However, more than $2 \%$ of fibre content tends to decrease the compressive strength and modulus of elasticity.

- Direct tensile strength of the UHPFRC seemed to increase gradually with increasing content of fibres up to the $3 \%$.

- With an increase in target mechanical parameters, UHPC and UHPFRC become much more sensitive to quality of the components, the dispersion of the particles, mixing procedure, the specimen preparation and curing.

- Fibre reinforced concrete slabs tend to decrease the crater diameters by 42 to $50 \%$ than their plain concrete counterparts. Nevertheless, further increase of fibre content beyond $2 \%$ has no effect on reducing the crater diameter, as diameter of the crater tends to remain constant within $2 \%$ and $3 \%$ of fibre content.

- Addition of high strength fibres to the mixture enhanced the impact behaviour in terms of penetration compared to their plain concrete counterparts. However, any further increase of the fibre content beyond $1 \%$ has no reasonable effect on penetration depth of the projectile.

- Based on the previous results it was found that the addition of high-strength fibres enhanced the resistance to impact loading. It was found that the optimal amount of fibre content with respect to the mechanical properties, workability and resistance to projectile impact lies between $2 \%$ and $3 \%$ by volume.

\section{Acknowledgements}

The authors gratefully acknowledge the support provided by the Ministry of the Interior of the Czech Republic under project number VG20102014003. The authors would like to acknowledge the assistance of the technical staff of the Experimental Centre, CTU in Prague and students who participated on the project, namely, Marek Piskytl, Jaroslav Pokorny, Tomas Vavrinik and Jan Zatloukal.

\section{References}

[1] Cauberg, N., Piérard, J. and Remy, O. 2008, "Ultra High Performance Concrete: Mix design and practical applications".

[2] Wille, K., Naaman, A.E. and Parra-Montesinos, G.J. 2011, "Ultra-High Performance Concrete with Compressive Strength Exceeding $150 \mathrm{MPa}$ (22 ksi): A Simpler Way", ACI Materials Journal, vol. 108, no. 1, pp. 46-54.

[3] Graybeal, B.A. 2007, "Compressive behavior of ultra-high-performance fiber-reinforced concrete", ACI Materials Journal, vol. 104, no. 2, pp. 146-152.

[4] Habel, K., Charron, J., Braike, S., Hooton, R.D., Gauvreau, P. and Massicotte, B. 2008, "Ultra-high performance fibre reinforced concrete 
mix design in central Canada", Canadian Journal of Civil Engineering, vol. 35, no. 2, pp. 217-224.

[5] Rossi, P., Arca, A., Parant, E. and Fakhri, P. 2005, "Bending and compressive behaviours of a new cement composite", Cement and Concrete Research, vol. 35, no. 1, pp. 27-33.

[6] Habel, K. and Gauvreau, P. 2008, "Response of ultra-high performance fiber reinforced concrete (UHPFRC) to impact and static loading", Cement and Concrete Composites, vol. 30, no. 10, pp. 938-946.

[7] Bindiganavile, V., Banthia, N. and Aarup, B. 2002, "Impact response of ultra-high-strength fiber-reinforced cement composite", ACI Materials Journal, vol. 99, no. 6, pp. 543-548.

[8] Zhang, M., Shim, V., Lu, G. and Chew, C. 2005, "Resistance of highstrength concrete to projectile impact", International Journal of Impact Engineering, vol. 31, no. 7, pp. 825-841.

[9] Wang, N., Mindess, S. and Ko, K. 1996, "Fibre reinforced concrete beams under impact loading", Cement and Concrete Research, vol. 26, no. 3, pp. 363-376.

[10] Farnam, Y., Mohammadi, S. and Shekarchi, M. 2010, "Experimental and numerical investigations of low velocity impact behavior of highperformance fiber-reinforced cement based composite", International Journal of Impact Engineering, vol. 37, no. 2, pp. 220-229.

[11] Maalej, M., Quek, S.T. and Zhang, J. 2005, "Behavior of Hybrid-Fiber Engineered Cementitious Composites Subjected to Dynamic Tensile Loading and Projectile Impact", Journal of Materials in Civil Engineering, vol. 17, no. 2, pp. 143-152.

[12] Vejmelkova, E., Konvalinka, P., Padevet, P., Kopecky, L., Keppert, M. and Cerny, R. 2009, "Mechanical, Hygric, and Thermal Properties of Cement-Based Composite with Hybrid Fiber Reinforcement Subjected to High Temperatures", International Journal of Thermophysics, vol. 30, no. 4, pp. 1310-1322.

[13] Hanchak, S., Forrestal, M., Young, E. and Ehrgott, J. 1992, "Perforation of concrete slabs with $48 \mathrm{MPa}$ (7 ksi) and $140 \mathrm{MPa}(20 \mathrm{ksi})$ unconfined compressive strengths", International Journal of Impact Engineering, vol. 12, no. 1, pp. 1-7.

[14] Vossoughi, F., Ostertag, C.P., Monteiro, P.J.M. and Johnson, G.C. 2007, "Resistance of concrete protected by fabric to projectile impact", Cement and Concrete Research, vol. 37, no. 1, pp. 96-106. 